\title{
Urgences
}

\section{Il n'y a plus de destinataire à cette adresse}

\section{Geneviève Amyot}

Numéro 33, octobre 1991

Poésies parallèles : France - Québec

URI : https://id.erudit.org/iderudit/025658ar

DOI : https://doi.org/10.7202/025658ar

Aller au sommaire du numéro

Éditeur(s)

Urgences

ISSN

0226-9554 (imprimé)

1927-3924 (numérique)

Découvrir la revue

Citer ce document

Amyot, G. (1991). Il n'y a plus de destinataire à cette adresse. Urgences, (33). https://doi.org/10.7202/025658ar d'utilisation que vous pouvez consulter en ligne.

https://apropos.erudit.org/fr/usagers/politique-dutilisation/ 


\section{Il n'y a plus de destinataire à cette adresse Geneviève Amyot}

Je t'avais apporté un petit tournesol. Poussé chez moi, dans un mince espace de terre pauvre le long du cabanon. Je devinais bien, pourtant, que je n'oserais pas ce geste. Ou encore on ne sait jamais, une petite opportunité et tout devient simple. Ou peut-être y aurait-il lieu de forcer le courage. Jai donc cassé le petit tournesol. À la main. Après avoir bien réfléchi mon choix. Pas de bouton le long de la tige. Tu aurais parfaitement compris. La plupart de ces boutons n'arriveront pas à terme c'est clair, mais il convient de mettre toutes les chances de ce côté-ci des choses. Tant que nous y sommes.

Et je songeais, en route pour cette rencontre dernière, comme tu aurais aimé cette audace de fleur-soleil inusitée parmi les bouquets convenus. Mais ce rite n'aurait eu, à ce moment précis, ni sa pureté, ni son poids, ni sa suffisante discrétion. Je me suis donc contentée de l'imaginer, tu aurais été d'accord aussi. J'aurais pu cependant te le laisser en ta terre, en toute intimité, une fois les autres partis, j'ai hésité, mais ca n'était plus ainsi, tout à coup, qu'il en devait être.

Quand je suis rentrée, le petit tournesol était toujours là, sur le banc du passager, molli, étrange, rabougri. Ma fille l'y a trouvé quelques instants plus tard, elle a réclamé de l'eau, j'ai retaillé la tige, il a repris; il est encore à la fenêtre, face au fleuve, un peu plus gros il me semble mais c'est sans doute parce que j’ose maintenant le regarder de plus près. Quant à la petite, elle ne savait pas même à ce moment d'où je venais, elle a voulu sauver une fleur et c'est tout, comme quand elle veut chauffer les oiseaux froids... Moi aussi, tu sais, quand ils m'ont appris la nouvelle, ma première idée a été de t'offrir de la soupe. De la crème de chou-fleur, c'est la saison, je venais juste de faire une si délicieuse crème de chou-fleur. Et je cuis encore mon pain. J'ai pensé me mettre à la tâche et t'apporter du pain. Cela non plus je ne l'ai pas fait.

La petite est entrée à l'école. En première oui. C'est la plus grande de sa classe. J'aurais tant aimé te dire cela, que la petite est maintenant à l'école, et la première journée j'ai 
pleuré en étendant mon linge. J'aurais aimé te dire cela, quelle négligence de ne pas être venue plus tôt, et toi comment vas-tu, ca fait longtemps, mais non tu ne vieillis pas, tu es splendide... J'avais tant à te dire à propos de l'enfance, et de la métamorphose. Toutes ces petites fins du monde, sans répit. Et tant de ferveurs... Ses deux palettes sont tombées. Ça lui fait un grand trou, espiègle et émouvant. Je l'ai fait photographier juste avant, c'est très bon, son dernier visage de petite enfant. Ils nous ont donné trois médaillons. Javais d'abord pensé en porter un, je l'ai enlevé juste au moment d'aller cueillir le tournesol.

Il y a vingt ans, en un semblable, mais si semblable automne, tu entreprenais de me prendre par la taille. Ma petite vieille vivait encore, nous devions aller souper chez elle la semaine prochaine, tu te rappelles, mais il y a eu cet accident, il y a vingt ans, elle est loin, mais à la fois si intime, passée dans mes placentas, dans mon lait, mes chansons, dans mes veilles, c'est elle que je sollicitais dans mes veilles quand il semblait tout à coup que le corps ne répondrait plus, si manquante, si familière je t'assure, passée dans la moindre de mes caresses sur leurs épaules, leurs joues, sur leurs pieds, dans chacun des premiers mots qu'ils ont écrits, dans les plasteurs et dans l'onguent, j'aurais tant aimé te dire, et qu'elle y sera, je n'ai nul doute, et plus encore, au moment du premier sang de la petite, c'est elle qui fournira le linge, tant de tendresse, c'est elle qui me signifiera ensuite, par la simple bonté de l'œil, de me retirer quelque peu... Il y a vingt ans. Elle me prenait encore par la taille. Et toi...

Tu as vu la grosseur de cette lune, c'est incroyable, cette lumière si finement couverte, une clarté qui se livre en douceur, immobile, simple, durable, et il n'y a que toi pour le savoir à ma guise, et comme l'air est bon, et cette apaisante odeur de l'herbe, de la terre humide dans la fraîcheur encore possible du soir qui s'écourte, il n'y a que toi pour sentir ainsi le soir qui s'écourte, et... heureusement... tu es là... inchangé... tu es là tout à coup, le temps n'a pas passé, le temps curieusement n'a rien touché, tu es là, tout est d'une précision impeccable, la finesse de tes lèvres, la subtilité des coins pour les demi-sourires, l'emplacement de la pointe lumineuse en chacun de tes yeux, ce fin duvet à l'arête du nez, si tant est bien sûr que s'y pose la lumière, le rose de la pudeur au 
sommet des joues quand l'amour s'installe en tes souffles, tout est sauf, le modelé des cuisses sous l'étoffe au moment de la jambe croisée, la chaleur bienfaisante de la poitrine et des bras, cette délicatesse attentive du dedans des doigts, notre quête, ta chevelure, ton envoûtante chevelure. Et comme tu riais... J'aurais voulu te dire tout ce que j'ai gardé de tes offrandes, et le temps passé sur ma jeunesse, et que j'ai pleuré en étendant mon linge, et que nous sommes intacts. Tu vois, j'ai encore ce petit corps maigre et blême que tu avais investi de ton espérance, quelques rides mais qu'importe, je continue de faire la folle et de me ficher des règles, de faire des bouts de trottoir sur une patte et de parler toute seule quand je marche sur la grève, maintenant c'est surtout quand j'épluche mes patates, je n'ai plus beaucoup le temps d'aller seule sur la grève mais qu'importe, je te dis que nous sommes intacts, tu es là... Il conviendrait tant que tu y sois... Ce soleil de début d'automne, mes tournesols qui le boivent avec un entêtement de moines en prière... Je ne puis porter atteinte au mystère de ton destin mais c'est le temps des pommes, des citrouilles, l'alyssum est au meilleur de son parfum, tout est encore d'un vert impeccable, tu aurais pu loger il me semble encore tant d'autres roses, justement je cherchais conseil à propos des roses, je ne réussis pas très bien, je t'aurais montré les photos de la petite, si tu voyais cette chevelure, et Jérôme fait de l'unicycle, une sorte de petite magie simple, tu aurais été charmé, toi qui sais si bien la grande gravité des petites choses, leur charge de tendresse et de songe, par exemple, à l'école, ils ont déjà vu le $i$, le $o$, le $a$, et le $e$, c'est très beau sur ses pages, elle est tout excitée, elle m'assure que oui, elle commence bien par le bon bout, je viens les larmes aux yeux... Bien sûr, l'enfance... Et nous avions pourtant dès lors montré nos clefs, tachées chacune aux secrets indélébiles de nos chambres interdites, ma mère si tôt perdue, les grands désordres de nos pères, cette petite sœur, dix-huit ans, je me souvenais mais j'ai vérifié sur la plaque, dix-huit ans, tu y pensais tous les jours encore me disais-tu, je t'ai regardé sans effroi descendre au même jardin, lui m'étreignait fortement par l'épaule, nous étions nombreux, tes hommes, tes femmes, tes frères, tes enfants, atterrés, sombres et nombreux, il t'a chauffé un peu de terre entre ses doigts, je me suis retirée, après nous avons juste parlé un peu du temps passé, et de l'incroyable beauté des fleurs. 
J'aurais tant voulu nous dire... ce que l'âge en nous nettoie et simplifie, ce que nous avions à ce moment escamoté de la détresse, et de l'amour, ce que nous n'avons pas pu accomplir de la consolation... et que par-delà l'offense et la blessure demeure à jamais, dans l'ordre sacré de la quête et de la connivence, une vivante, essentielle affection.

Je ne sais pas où tu te trouves, ni même si tu te trouves quelque part ailleurs maintenant qu'en cette terre auprès des autres avant toi; je n'ai pas de croyance, juste une petite indispensable, inévitable espérance. Mais si jamais, en je ne sais quel parcours énigmatique, tu croisais par hasard notre jeunesse, fais-moi signe je t'en supplie... Je vois une jupe fine, mais sans cérémonie. Tbi, bien sûr, une chemise mauve. Les pieds seront nus. La lumière: dissoute et subtile, sans mouvements. Comme résolue. La petite vieille se tiendra à notre droite, un peu floue mais souriante, modestement, si discrètement souriante. Et en ce qui concerne l'odeur inouie du muguet, rien non plus ne sera jamais changé. 